\title{
Digital elevation models on accuracy validation and bias correction in vertical
}

\author{
Kwanchai Pakoksung ${ }^{1} \cdot$ Masataka Takagi $^{1}$
}

Received: 11 December 2015/Accepted: 15 December 2015/Published online: 24 December 2015

(C) Springer International Publishing Switzerland 2015

\begin{abstract}
Digital Elevation Model (DEM) is used to represent the terrain of the earth. A free provided DEMs are the $10 \mathrm{~m}$ DEM produced by the Geographical Survey Institute of Japan (GSI-DEM), Advanced Space Borne Thermal Emission and Reflection Radiometer-Global DEM, Shuttle Radar Topography Mission, Global Multiresolution Terrain Elevation Data 2010, Hydrological data and maps based on Shuttle Elevation Derivatives at multiple Scales, and Global 30 Arc-Second Elevation that are actually used in scientific studies. DEMs have made a high accuracy to assess an error using an observation elevation point. The DEMs in this study at an original spatial resolution of the Shikoku Island, Japan were collected that were evaluated and corrected by using the referent elevation points observed by global position system. The evaluation and correction method of the DEMs were based on the statistical measures and linear transformation algorithm respectively. The results reveal that the GSI-DEM has higher accuracy than the five DEMs, and these DEMs have gotten more accuracy after corrected by the transform's parameters. This approach will be used to recommend for a new DEM in a future, and it can be applied for making a high accuracy DEM to model the earth's terrain.
\end{abstract}

Kwanchai Pakoksung

178011e@gs.kochi-tech.ac.jp

Masataka Takagi

takagi.masataka@kochi-tech.ac.jp

1 Infrastructure Systems Engineering, Kochi University of Technology, Tosayamada, Kami City, Kochi 782-8502, Japan
Keywords Digital elevation models · Accuracy assessment · Linear transformation · Shikoku Island · Japan

\section{Introduction}

Digital Elevation Model (DEM) is an important factor in assessing in any process using digital topography analysis, including slope, curvature, roughness and local relief that are its derivative attributes. The parameters are normally utilized in several applications such as flood simulation (Pakoksung and Takagi 2015), landslide mapping (Dhakal et al. 2000) and seismic wave propagation (Lee et al. 2009). DEM can be created by using various methods, for example, Stereoscopic Photogrammetry of Air-Borne or SatelliteBorne, RADAR or SAR interferometry, Light Detection and Ranging (LIDAR), and conventional surveying (GPS or GNSS). Each method that has a limitation depends on price, accuracy, sampling density, preprocessing requirements. Each DEM is normally made by using four steps such as data acquisition ( $\mathrm{Li}$ et al. 2006), resampling to grid spacing, interpolation a height of a point and DEM representation, repeating and accuracy assessment. An error of the resulting DEMs can be introduced by all of step for generating to mention above. These errors have been investigated on a gridded of data sets and classified by gross errors, systematic errors and random errors (Fisher and Tate 2006).

The error in several DEM data is widely explored on reasons and significances, which a quality of DEM be influenced by on several factors, as well as sensor types, algorithm, terrain type, grid spacing and characteristics (Hebeler and Purves 2009). A variety of DEMs on free provided data, including the $10 \mathrm{~m}$ DEM produced by the Geographical Survey Institute (GSI) of Japan (GSI-DEM), Advanced Space Borne Thermal Emission and Reflection 
Radiometer-Global Digital Elevation Model (ASTER GDEM), Shuttle Radar Topography Mission (SRTM), Global Multi-resolution Terrain Elevation Data 2010 (GMTED2010), Hydrological data and maps based on Shuttle Elevation Derivatives at multiple Scales (HydroSHEDS) and Global 30 Arc-Second Elevation (GTOPO30) is useful to model nearly the terrain of earth in worldwide. Methods for DEM validation have been investigated in a previous study (Gonga-Saholiariliva et al. 2011). One approach of investigation, accuracy of a DEM depends on the location and this accuracy can be assessed by using comparison between the DEM and the reference point that is measured by using high precision equipment as Global Positioning System (GPS) on a ground survey (e.g., Jarvis et al. 2004; Miliaresis and Paraschou 2005; Hirt et al. 2010; Kolecka and Kozak 2013; Forkuor and Maathuis 2012; Nikolakopoulos et al. 2006).

An accuracy of DEM indicates an important point in several applications and to examine their reasonability based on statistical measurement for certain applications. The freely provided six DEM products over Shikoku Island, Japan were investigated on a vertical accuracy of this research. In addition, we applied the Geometric Transformation method to the correct the products to achieve a better agreement of topography data sets.

This paper is organized as follows. "Introduction" section explains the motivation of this study; "Test area and data" section shows data sets and study area; "Methodology" section presents methodology; "Results and discussion" section reports our results and discussion; final "Conclusion" section conclusions.

\section{Test area and data}

\section{Test area}

Shikoku in Japan is selected as validation area. The Shikoku (Fig. 1) is the 4th island of Japan located in the western territory within a bounding rectangle defined by the geographic coordinates $30^{\circ} \mathrm{N}$ to $35^{\circ} \mathrm{N}$ and $130^{\circ} \mathrm{E}$ to $135^{\circ} \mathrm{E}$. This area about $18,800 \mathrm{~km}^{2}$ is represented by a remote and mountainous condition to make the area extremely in the need of validation. The elevation ranges from approximately 0-1982 $\mathrm{m}$. MSL, and the average slope is $8-30^{\circ}$ based on SRTM DEM. The principal land cover type is forests that are occupy in mountain slopes (Kyaw and Takagi 2010).

\section{Digital elevation models}

Six free source DEM on different accuracy and coverage were used for this study (see Table 1) which are the $10 \mathrm{~m}$
DEM produced by the Geographical Survey Institute (GSI) of Japan (GSI-DEM), Advanced Space Borne Thermal Emission and Reflection Radiometer-Global Digital Elevation Model version 2 (ASTER GDEM), the Consultative Group for International Agriculture Research Consortium for Spatial Information Shuttle Radar Topographic Mission version 4.1 (SRTM), Global Multi-resolution Terrain Elevation Data 2010 (GMTED2010), Hydrological data and maps based on Shuttle Elevation Derivatives at multiple Scales (HydroSHEDS) and Global 30 Arc-Second Elevation (GTOPO30).

GSI-DEM is generated by using digitized topographic maps based on scales between 1:5000 and 1:25,000 (Tachikawa et al. 2011). This DEM was published for freely available on 2008 only Japan region. The GSI-DEM is provided at $10 \mathrm{~m}$ resolution based on Japan Geodetic Datum 2000 (JGD2000). The absolute vertical accuracy is $5 \mathrm{~m}$, and its data sets are in the Geospatial Information Authority of Japan, from 393 indexes were downloaded for the Shikoku Island (Fig. 2a).

ASTER GDEM was created by the METI (Ministry of Economy, Trade, and Industry) of Japan and the NASA (National Aeronautics and Space Administration). This DEM was published for freely available on 29 June 2009 (Team 2012). The ASTER GDEM is freely provided at a resolution as one arc-second (about $30 \mathrm{~m}$ ) and its coordinate system is based on World Geodetic System 1984 (WGS84). The absolute vertical accuracy of the ASTER DEM at $95 \%$ confidence level is about $20 \mathrm{~m}$. Data Pool at the NASA Land Processes Distributed Active Archive Center (LP DAAC) contains the ASTER GDEM data set (Team 2012) that an index No. N32E132, N32E133, N33E132, N33E133, N33E134, N34E132, N34E133 and N34E134 (Fig. 2b) covering the Shikoku Island, were downloaded.

SRTM of the US Geological Survey (USGS), this data was originated by a project between the National Imagery and Mapping Agency (NIMA) and the National Aeronautics and Space Administration (NASA). This DEM is observed from radar interferometry using two radar images from shuttle with a slightly different location. The Endeavour space shuttle observed the terrain of the Earth based on 3D during February 2000. The radar instrument was installed by 2 components, dual Space Borne Imaging Radar (SIR-C) and dual X-band Synthetic Aperture Radar (X-SAR). This observation using radar composite had collected the terrain data over $80 \%$ of the Earth based on three arc-seconds (about $90 \mathrm{~m}$ ), covering latitude $60^{\circ}$ north to $56^{\circ}$ south. A vertical and horizontal accuracy at $90 \%$ confidence of the SRTM are $16 \mathrm{~m}$ to evaluate in a linear error and $20 \mathrm{~m}$ to assess with a circular error, respectively (Jarvis et al. 2012). This DEM product has available online on the Consultative Group for International Agriculture 


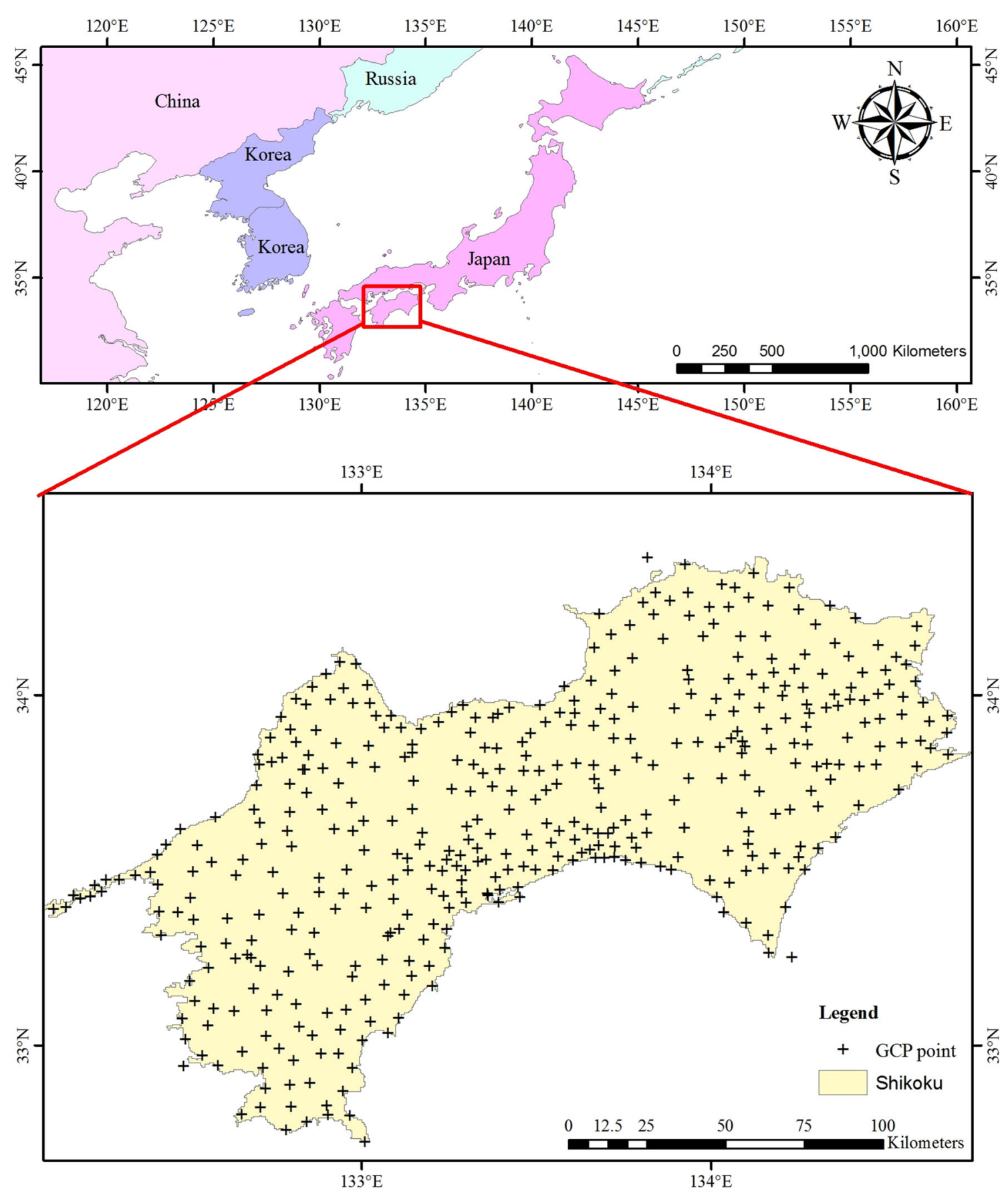

Fig. 1 The location of Shikoku Island, Japan

Research Consortium for Spatial Information (CGIARCSI) to download data, from which an index No. 6306 (Fig. 2c) were downloaded over the Shikoku Island.

GMTED2010 was distributed by the US Geological Survey (USGS) and the National Geospatial-Intelligence Agency (NGA). This DEM was provided in 2010 (Danielson and Gesch 2011) to replace the GTOPO30 at 30 arc-seconds data for developing of a new global elevation model. The fusion technique is used to establish the
GMTED2010 from 11 raster based elevation sources. This data with absolute vertical accuracy as $26-29 \mathrm{~m}$ on the RMSE is produced as three separate resolutions of 30 arcseconds, 15 arc-seconds, and 7.5 arc-seconds (Carabajal et al. 2011). The GMTED2010 in LP DAAC on an index No. 30N120E was downloaded for the Shikoku Island (Fig. 2d).

HydroSHEDS has been developed by a joint project of the Conservation Science Program of World Wildlife Fund 
Table 1 Characteristics of DEMs source

\begin{tabular}{|c|c|c|c|c|c|c|}
\hline Data & GSI-DEM & ASTER & SRTM & GMTED 2010 & HydroSHEDS & GTOPO30 \\
\hline Data source & Topo-map & ASTER & Space shuttle radar & GTOPO & SRTM & $\begin{array}{l}\text { Organizations } \\
\text { around the world }\end{array}$ \\
\hline $\begin{array}{l}\text { Generator and } \\
\text { distribution }\end{array}$ & GSI & METI/NASA & NASA/USGS & USGS & WWF/USGS & USGS \\
\hline Release year & 2008 & 2009 & 2003 & 2010 & 2009 & 1993 \\
\hline Posting interval & $10 \mathrm{~m}$ & $30 \mathrm{~m}$ & $90 \mathrm{~m}$ & $225 \mathrm{~m}$ & $500 \mathrm{~m}$ & $1000 \mathrm{~m}$ \\
\hline $\begin{array}{l}\text { DEM accuracy } \\
\text { (SD) }\end{array}$ & $\begin{array}{l}5 \mathrm{~m} \text { (Tachikawa } \\
\text { et al. 2011) }\end{array}$ & $\begin{array}{l}\text { 7-14 m (Team } \\
\text { 2012) }\end{array}$ & $\begin{array}{l}10 \mathrm{~m} \text { (Jarvis } \\
\text { et al. 2012) }\end{array}$ & $\begin{array}{l}29 \text { m (Carabajal } \\
\text { 2011) }\end{array}$ & None & $30 \mathrm{~m}$ (USGS 2008) \\
\hline DEM coverage & Japan & $83 \mathrm{dN}-83 \mathrm{dS}$ & $60 \mathrm{dN}-60 \mathrm{dS}$ & $60 \mathrm{dN}-60 \mathrm{dS}$ & $60 \mathrm{dN}-60 \mathrm{dS}$ & $90 \mathrm{dN}-90 \mathrm{dE}$ \\
\hline
\end{tabular}
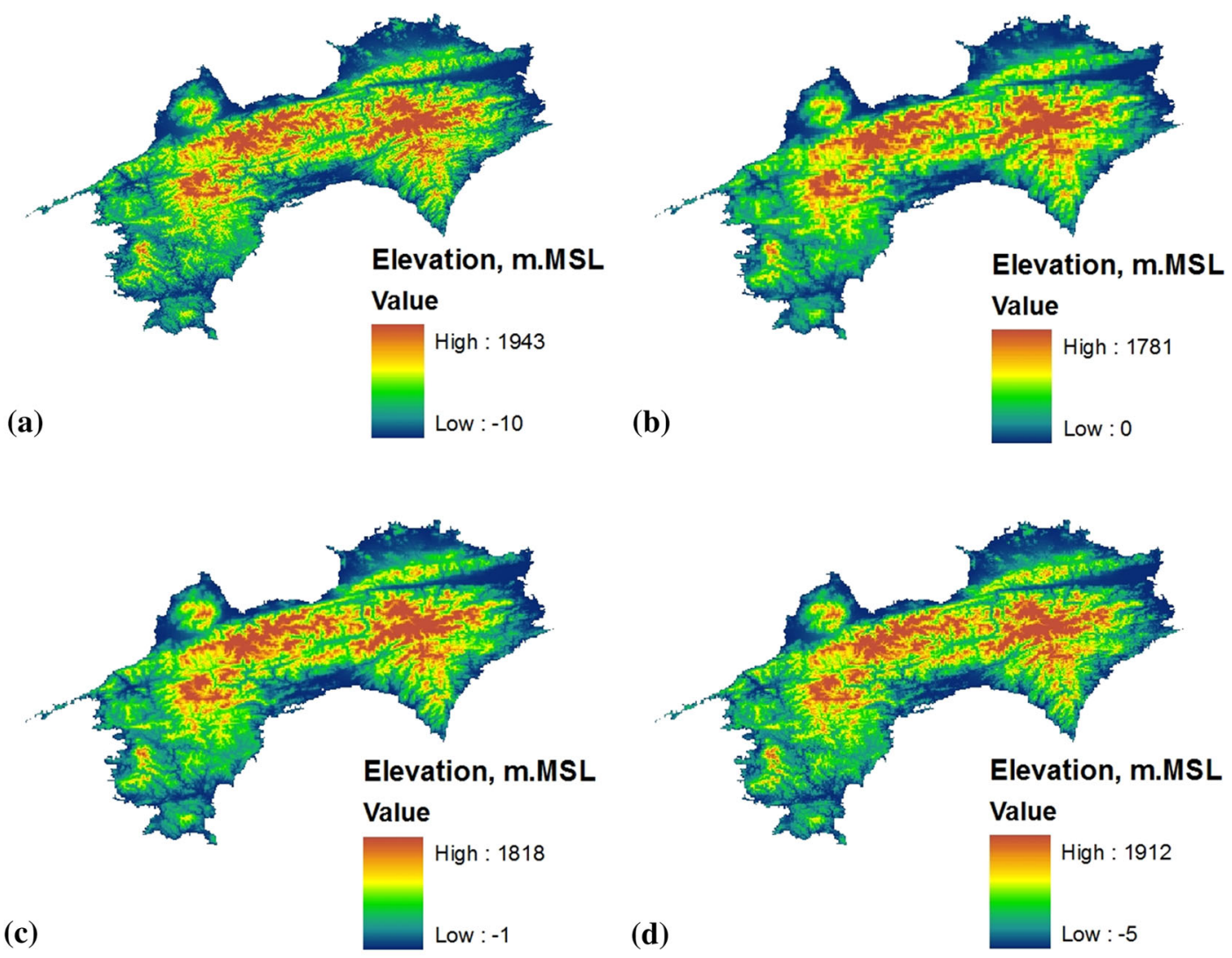

(d)
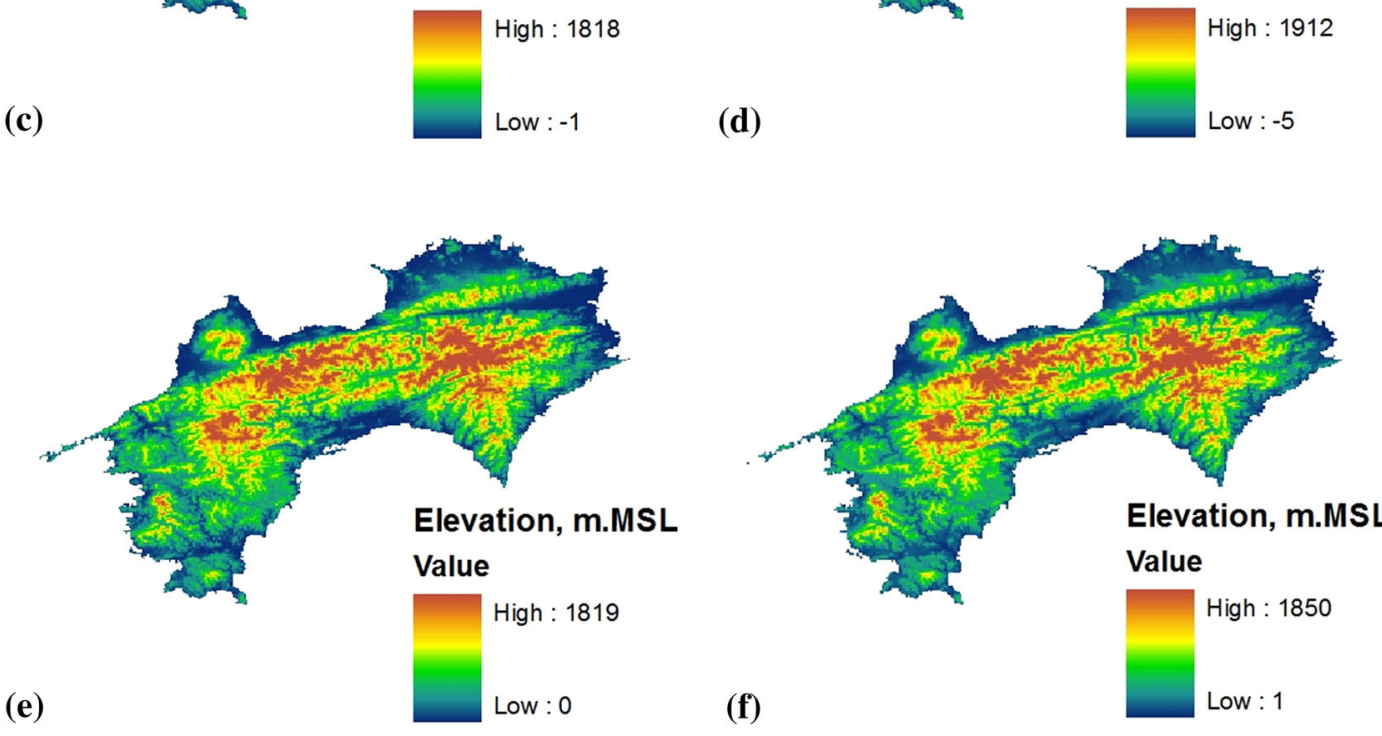

Fig. 2 Digital elevation models in the Shikoku Japan a GSI-DEM; b ASTER; c SRTM; d GMTED2010; e HtdroSHEDS; f GTOPO30 
(WWF), in partnership with the US Geological Survey (USGS), the International Centre for Tropical Agriculture (CIAT), The Nature Conservancy (TNC), and the Center for Environmental Systems Research (CESR) of the University of Kassel, Germany. The main funding for this project was provided to WWF by JohnsonDiversey, Inc. This DEM in global-scale applications provides hydrographic information and offers a geography data sets, including flow drainage directions, flow accumulations, and river topology information. The HydroSHEDS is developed from three arc-second resolution of the SRTM DEM that have been hydrologically conditioned by using a procedures to use void-filling, filtering, stream burning, and upscaling methodology (USGS Data sources of HydroSHEDS 2008; Lehner 2013). The main objective to develop the HydroSHEDS was to create feature supporting a regional and global watershed analyses and it produced a resolutions range from three arc-seconds (about $90 \mathrm{~m}$ ) to 5 arc-min (about $10 \mathrm{~km}$ ). This DEM product on 15 arc-seconds (about $500 \mathrm{~m}$ ) in Fig. 2e covering Asia region was downloaded for the Shikoku Island to use in this study.

GTOPO30 is a global DEM for free available on 1993 publishing from US Geological Survey (USGS 2008; Nawarathna NMNSB et al. 2001). This DEM is normally spaced at 30 arc- seconds resolution (about $1000 \mathrm{~m}$ ). The GTOPO30 is based on the WGS84, covering a latitude $90^{\circ}$ south to $90^{\circ}$ north, and a longitude from $180^{\circ}$ west to $180^{\circ}$ east. The vertical elevation above the mean sea level is values range from -407 to $8752 \mathrm{~m}$. This produced data are suitable for several regional applications, which is on an index No. E100N40 was downloaded for the Shikoku Island (Fig. 2f).

\section{Reference elevation data}

DEMs accuracy assessment involves a various number of reference points on high accuracy to achieve reliable measures. According to the reference point's accuracy would be at least three times more accurate than the DEM elevations (Athmania and Achour 2014). For this study, the reference points were observed by using Global Positioning Systems with Virtual Reference System (GPS-VRS) survey techniques. The accuracy of GPS-VRS observation is less than $2 \mathrm{~cm}$. Observed GCP data (Fig. 1) are freely published from TAKAGI laboratory in Kochi University of Technology, summarizing about 562 points in the Shikoku Island, JAPAN. These data sets included information of 3-dimensional coordinates $(\mathrm{x}, \mathrm{y}$, and $\mathrm{z}$ ) with projection attribute, latitude and longitude with the geodetic datum, observed date, observation pictures and satellite images as ALOS PRISM/AVNIR2 (Uda and Takagi 2010) at URL:http://www.infra.kochi-tech.ac.jp/takalab/Information/ research/-GCPDB/GCPDB.html.

\section{Methodology}

The main objective of this study is to validate the accuracy of DEM sources that are made for more accuracy by using bias correction. The methodology of validation accuracy is that "Validation methods" section was shown by statistical measurement use for each DEM. The bias correction in "Correction methods" section is done by using a linear transformation of geometric to improve accuracy of the DEM.

\section{Validation methods}

In this study, the validation method was represented by using a statistical measurement (see Table 2). The vertical accuracy of the six DEMs was calculated from the differences corresponding between the value of the DEM pixel and the GPS point. Elevation error was estimated which positive differences denote the locations of the DEM elevation exceeded the GPS point elevation while negative errors ensue at the locations of the DEM elevation was under the GPS elevation. After the elevation error estimated, a statistical, maximum error (Max), minimum error (Min), Mean Error (ME), Standard Deviation Error (STD), and Root Mean Square Error (RMSE), were estimated. STD and RMSE are revealing of surface quality and offer perception into the distribution of deviations on the side of the mean value. The agreement level between derived elevation values of six DEMs and linear regression with correlation is used to evaluate in terms with GPS data.

A normality test is used to describe and compare the error distributions in each DEM. A Quantile-Quantile plots (Q-Q plots) based on the normal distribution are created for visual examination. The Q-Q plot is shown by using a scatter plot that quantile of the observation are located on the horizontal and the predicted normal values are set on the vertical axis. The best-fit in the linear relationship showed that the observed values were normally distributed (Zandbergen 2008). This test is also used in statistical evaluation to investigate whether data estimate from a normal distribution (Höhle and Höhle 2009).

Table 2 Description of validated statistical

\begin{tabular}{ll}
\hline Statistical & Description \\
\hline Elevation error & $Z_{\text {diff }}=Z_{D E M}-Z_{G C P}$ \\
Mean error & $M E=\frac{\sum_{i=1}^{n} Z_{\text {diff(i) }}}{n}$ \\
Standard deviation error & $S T D_{\text {err }}=\sqrt{\frac{\sum_{i=1}^{n}\left(Z_{\text {diff }}-M E\right)^{2}}{n-1}}$ \\
Root mean square error & $R M S E=\sqrt{\frac{\sum_{i=1}^{n}\left(Z_{\text {diff }(i)}\right)^{2}}{n}}$ \\
\hline
\end{tabular}




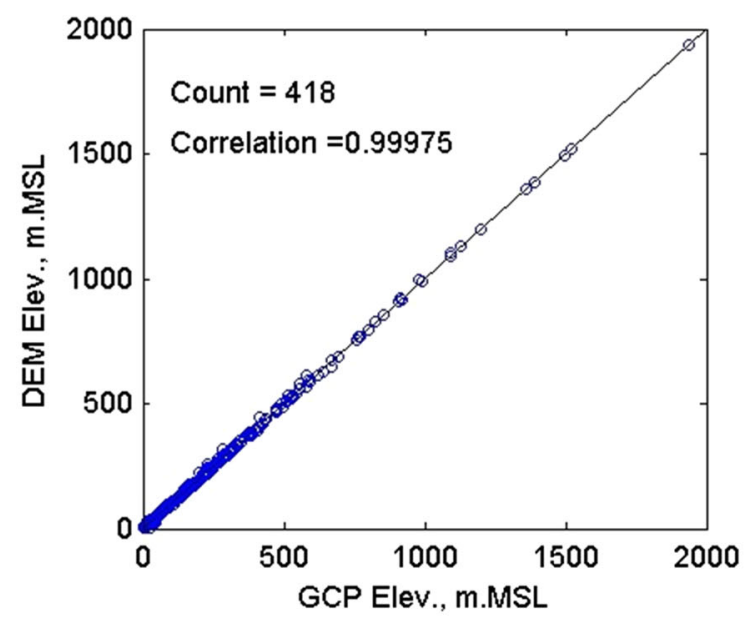

(a)

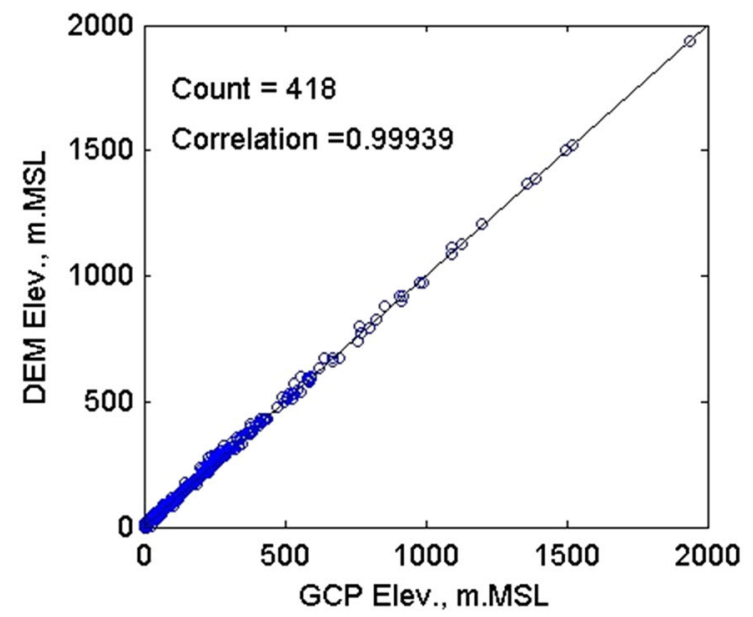

(c)

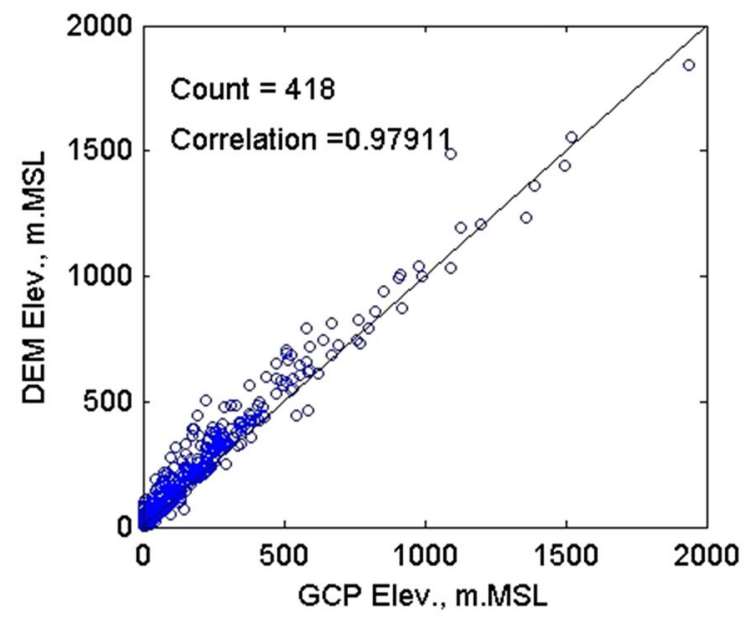

(e)

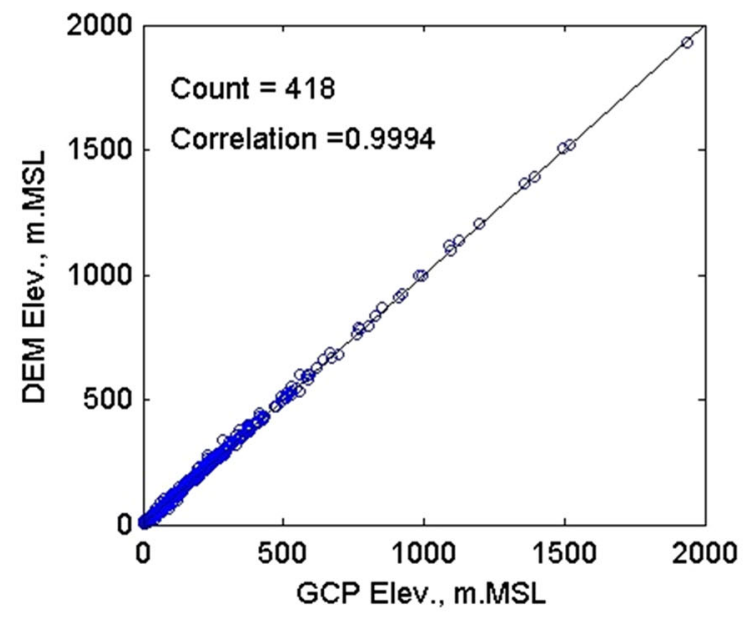

(b)

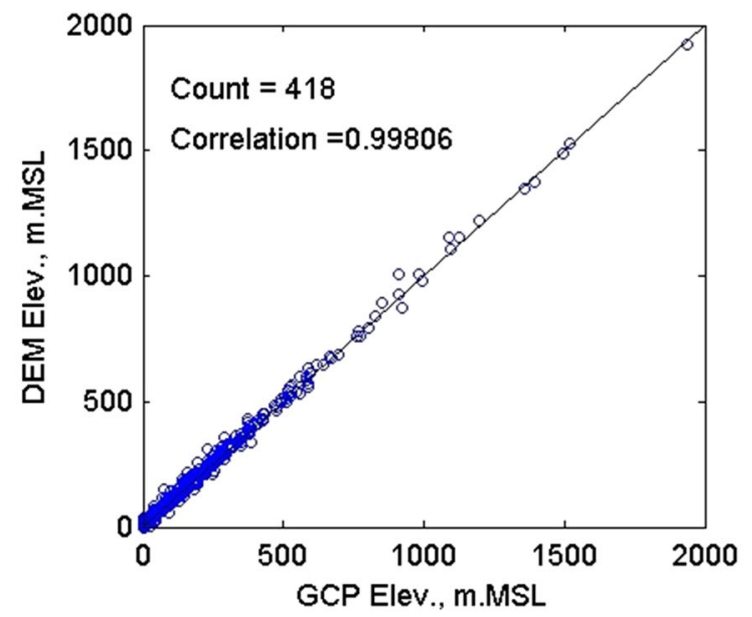

(d)

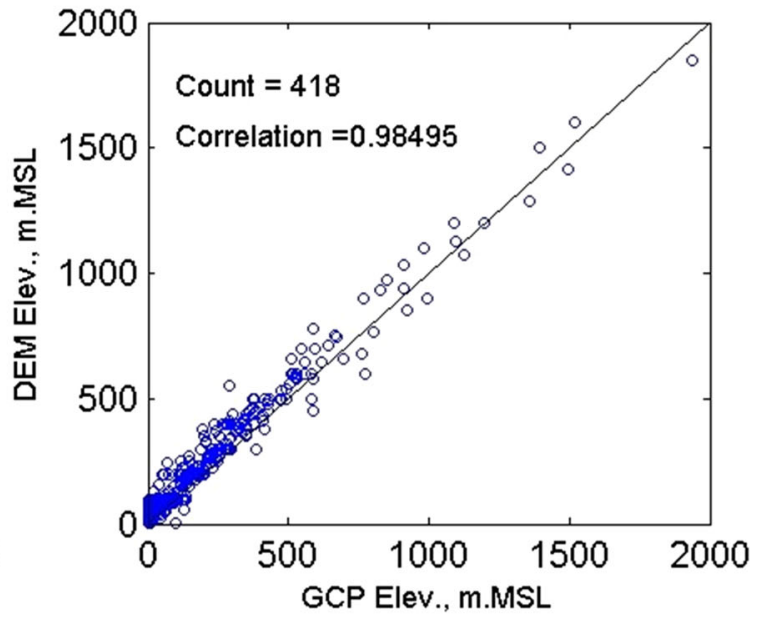

(f)

Fig. 3 Scatter plots between GCPs and a GSI-DEM; b ASTER; c SRTM; d GMTED2010; e HtdroSHEDS; f GTOPO30. The perfect fit is represented by the black line 


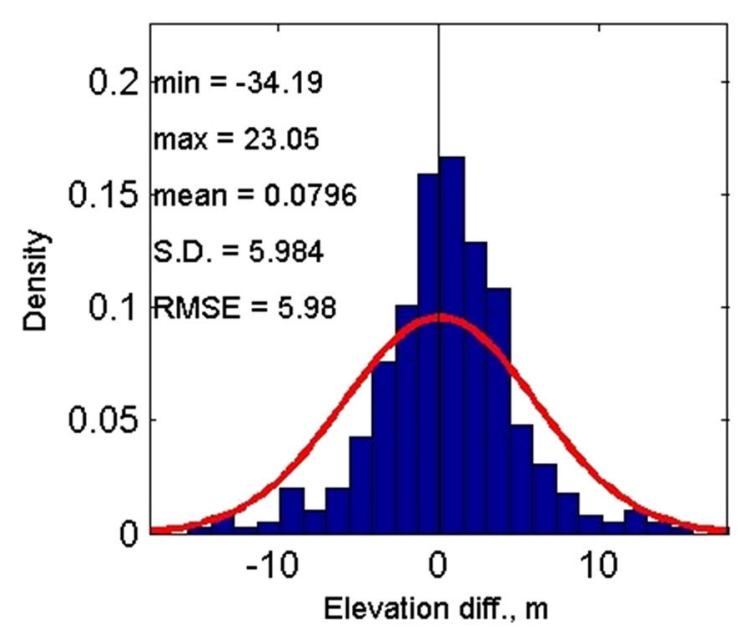

(a)

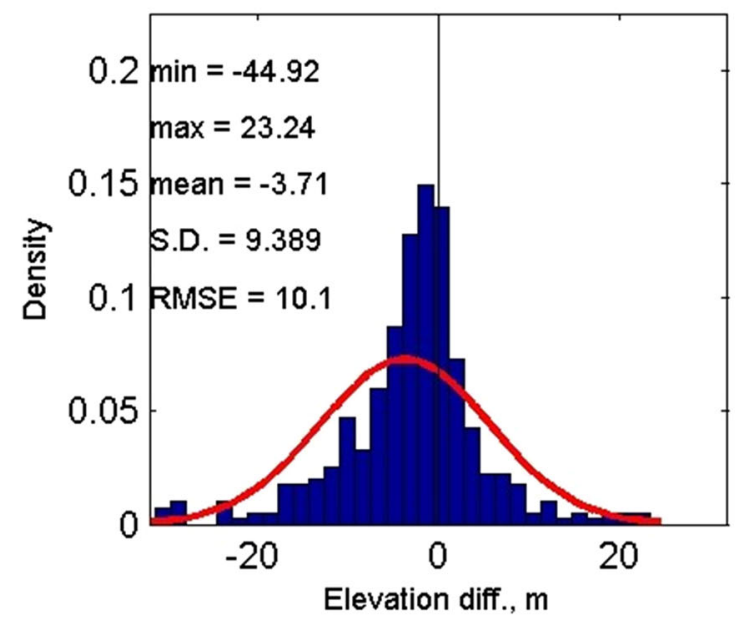

(c)

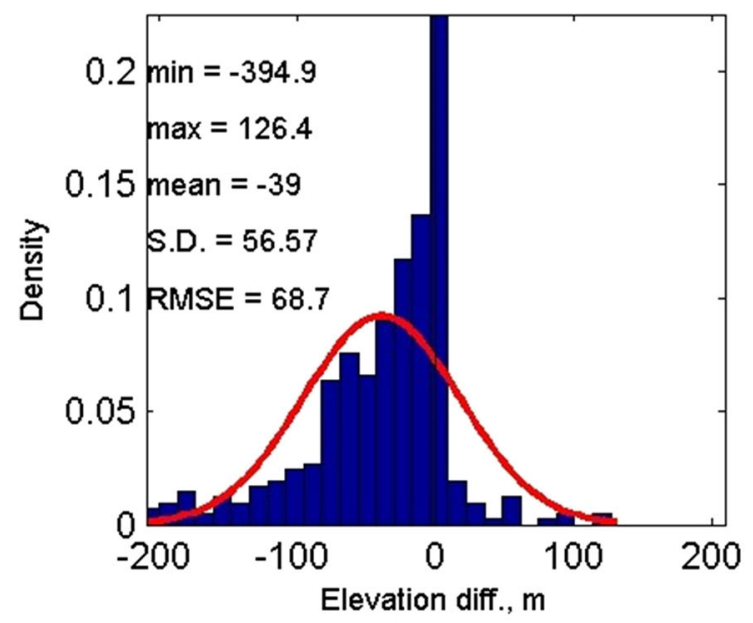

(e)

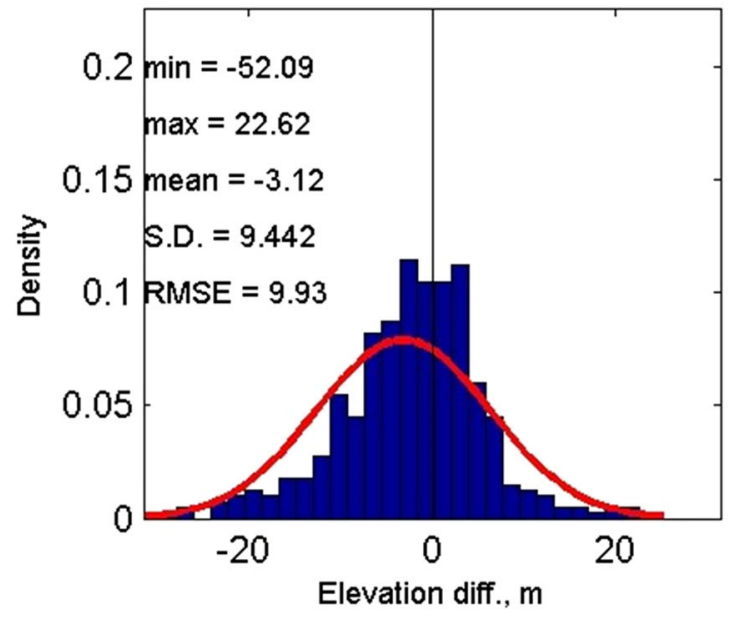

(b)

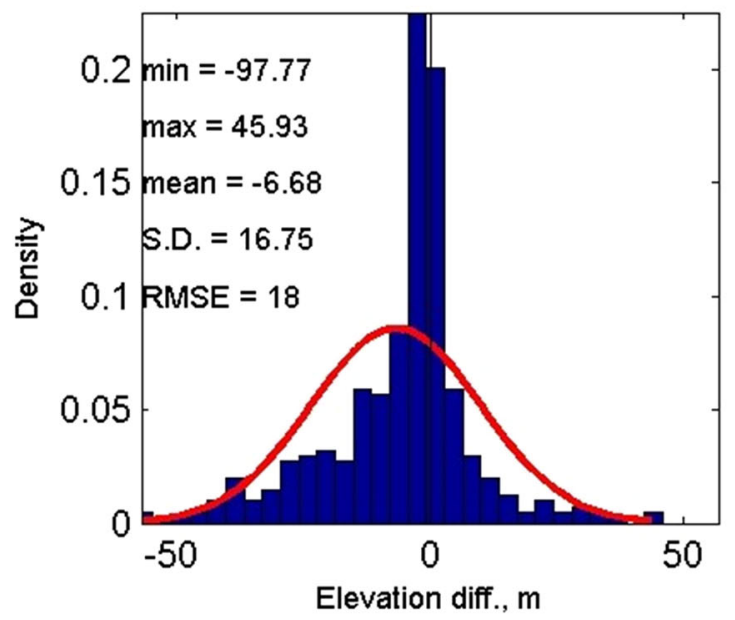

(d)

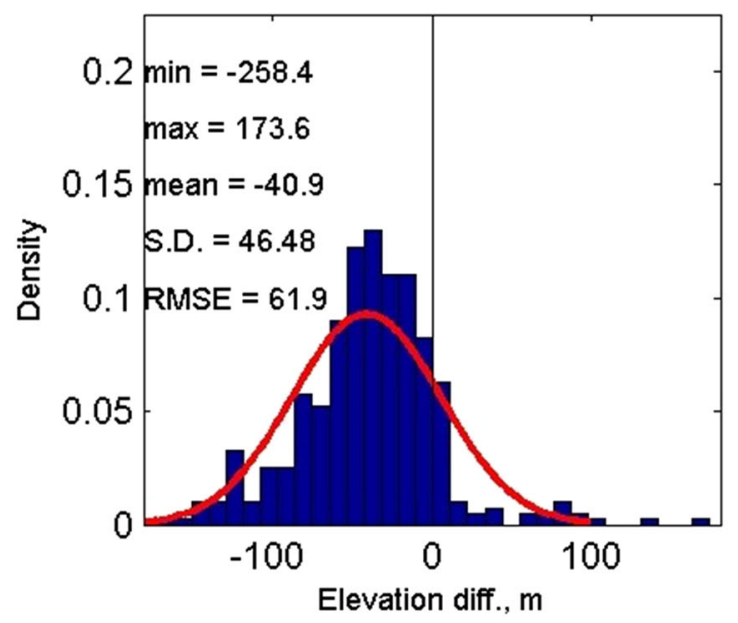

(f)

Fig. 4 Histograms of elevation errors and estimated basic statisticals. a GSI-DEM; b ASTER; c SRTM; d GMTED2010; e HtdroSHEDS; f GTOPO30. The continuous red line reveals the fitted curve based on normal distribution 
Table 3 Difference statistical between before and after bias correction (Units in meters)

\begin{tabular}{|c|c|c|c|c|c|c|c|c|c|c|}
\hline \multirow[t]{2}{*}{ DEMs } & \multicolumn{5}{|l|}{ Existing } & \multicolumn{5}{|c|}{ Bias correction } \\
\hline & Min & Max & $\mathrm{ME}$ & SD & RMSE & Min & Max & ME & SD & RMSE \\
\hline GSI & -34.19 & 23.04 & 0.08 & 5.98 & 5.97 & -32.69 & 23.22 & $-2.96 \mathrm{E}-10$ & 5.88 & 5.87 \\
\hline ASTER & -52.09 & 22.61 & -3.12 & 9.44 & 9.93 & -45.66 & 26.82 & $-2.16 \mathrm{E}-09$ & 9.09 & 9.08 \\
\hline SRTM & -44.91 & 23.24 & -3.71 & 9.38 & 10.08 & -40.72 & 28.92 & $-8.80 \mathrm{E}-10$ & 9.32 & 9.31 \\
\hline GMTED & -97.77 & 45.93 & -6.68 & 16.74 & 18.01 & -83.74 & 57.69 & $1.14 \mathrm{E}-09$ & 16.55 & 16.53 \\
\hline HydroSHEDS & -394.86 & 126.42 & -39.04 & 56.57 & 68.67 & -282.13 & 237.37 & $1.24 \mathrm{E}-09$ & 53.43 & 53.37 \\
\hline GTOPO & -258.42 & 173.59 & -40.90 & 46.47 & 61.86 & -212.03 & 222.19 & $-1.60 \mathrm{E}-11$ & 45.99 & 45.94 \\
\hline
\end{tabular}

\section{Correction methods}

Comparison with reference point measurements will be shown the most accurate DEMs product. However, two DEMs were differences with reference data that may be reduced. We obtained a bias correction equation to achieve a close fit between the six DEMs source and ground reference points. To accommodate for the finding that relative bias varied with total, a linear transformation function will be used to derive bias corrected of the DEMs elevation as follows in Eq. (1) on conceptual and Eq. (2) on application (Zhang and Zhang 2011; Kuriakose and Viswan 2013).

$Z=f(u, v, w)$

$Z=a \cdot u+b \cdot v+c \cdot w+Z_{0}$

where $Z$ is observation data, $u, v$ are coordinate of estimation, $w$ is estimation data, and $a, b, c$ and $Z_{0}$ are transformation parameter. Observation data at the first point until $n$ point are shown in Eq. (3) to (7) to summarize in Eq. (8).

$$
\begin{aligned}
& Z_{1}=a \cdot u_{1}+b \cdot v_{1}+c \cdot w_{1}+Z_{0} \\
& Z_{2}=a \cdot u_{2}+b \cdot v_{2}+c \cdot w_{2}+Z_{0} \\
& Z_{3}=a \cdot u_{3}+b \cdot v_{3}+c \cdot w_{3}+Z_{0} \\
& Z_{n-1}=a \cdot u_{n-1}+b \cdot v_{n-1}+c \cdot w_{n-1}+Z_{0} \\
& Z_{n}=a \cdot u_{n}+b \cdot v_{n}+c \cdot w_{n}+Z_{0}
\end{aligned}
$$

Summarize equation from the Eq. (3) to (7) as follows:

$\sum_{i=1}^{n} Z_{i}=\sum_{i=1}^{n}\left(a \cdot u_{i}+b \cdot v_{i}+c \cdot w_{i}+Z_{0}\right)$

Least square methods of Eq. (8) based on sum square error values $(E)$ are presented in Eq. (9).

$E=\sum_{i=1}^{n}\left(a \cdot u_{i}+b \cdot v_{i}+c \cdot w_{i}+Z_{0}-Z_{i}\right)^{2}$

To minimize sum square error by ordinary least square methods as follows: $\frac{\partial E}{\partial a}=0, \quad \frac{\partial E}{\partial b}=0, \quad \frac{\partial E}{\partial c}=0$, and $\frac{\partial E}{\partial Z_{0}}=0$

To represent in a matrix form are shown in Eq. (11).

$$
\begin{aligned}
& {\left[\begin{array}{llll}
\sum_{i=1}^{n} u_{i} \cdot u_{i} & \sum_{i=1}^{n} u_{i} \cdot v_{i} & \sum_{i=1}^{n} u_{i} \cdot w_{i} & \sum_{i=1}^{n} u_{i} \\
\sum_{i=1}^{n} u_{i} \cdot v_{i} & \sum_{i=1}^{n} v_{i} \cdot v_{i} & \sum_{i=1}^{n} v_{i} \cdot w_{i} & \sum_{i=1}^{n} v_{i} \\
\sum_{i=1}^{n} u_{i} \cdot w_{i} & \sum_{i=1}^{n} v_{i} \cdot w_{i} & \sum_{i=1}^{n} w_{i} \cdot w_{i} & \sum_{i=1}^{n} w_{i} \\
\sum_{i=1}^{n} u_{i} & \sum_{i=1}^{n} v_{i} & \sum_{i=1}^{n} w_{i} & n
\end{array}\right]\left[\begin{array}{c}
a \\
b \\
c \\
Z_{0}
\end{array}\right]} \\
& =\left[\begin{array}{l}
\sum_{i=1}^{n} Z_{i} \cdot u_{i} \\
\sum_{i=1}^{n} Z_{i} \cdot v_{i} \\
\sum_{i=1}^{n} Z_{i} \cdot w_{i} \\
\sum_{i=1}^{n} Z_{i}
\end{array}\right]
\end{aligned}
$$

The parameters $a, b, c$ and $Z_{0}$ were derived by minimizing between bias corrected value and ground observed point above the study area. The inverse matrix algorithm was used to obtain an optimized value of $a, b, c$ and $Z_{0}$ (Ishida and Takagi 2010).

\section{Results and discussion}

The correlation plots between GCP data and each DEM sources (Fig. 3) obtained for the test area; this plot is based on a selected 418 GPS points for sites. Results show that the six DEM sources have the same correlation coefficient on the reference elevation data point. All of the DEMs situations fit the conformation line, showing the excellent coefficient of correlation about 0.9. The distribution and number of selected points have affected by this situation.

Figure 4 show elevation differences between the modeled and observed data based on histograms. 


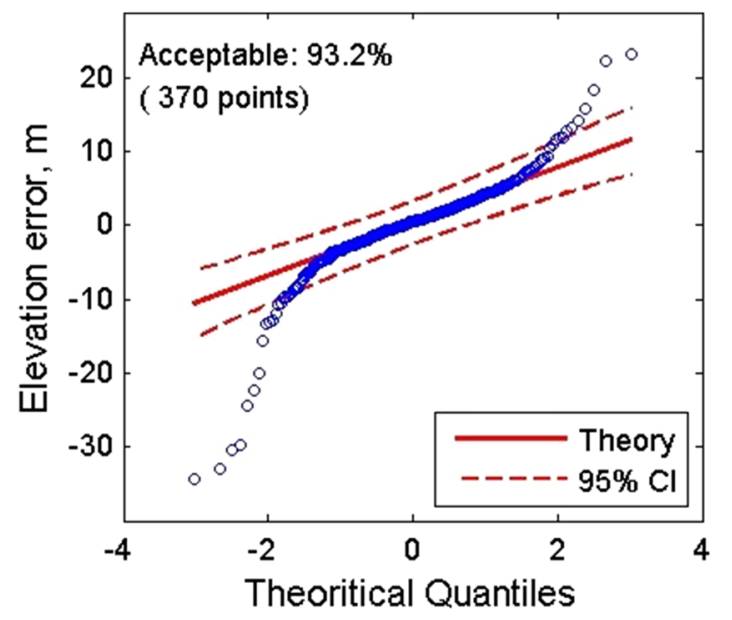

(a)

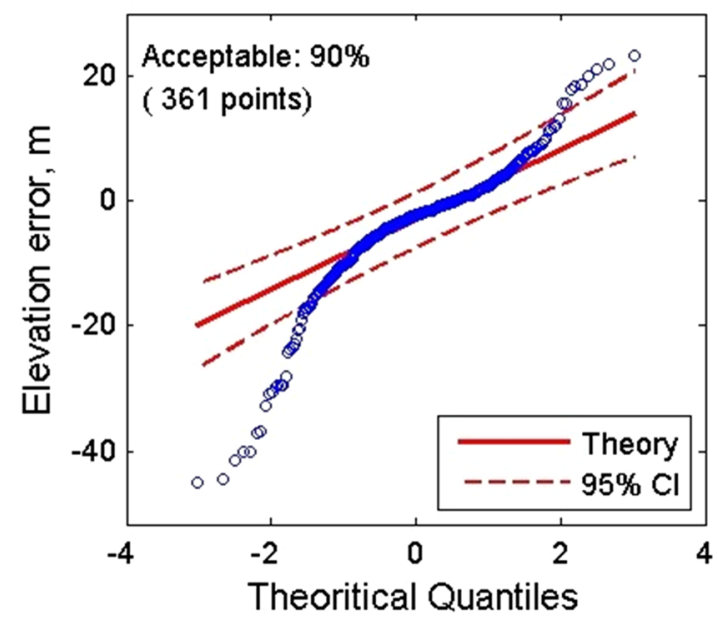

(c)

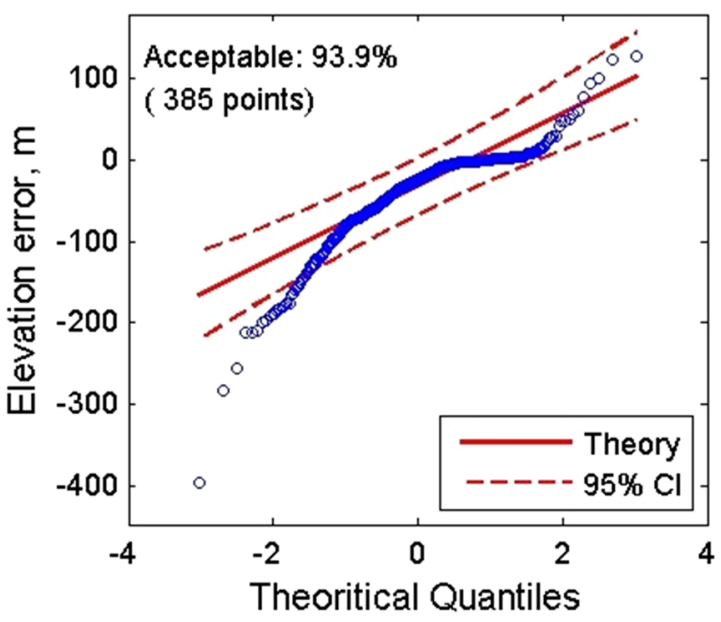

(e)

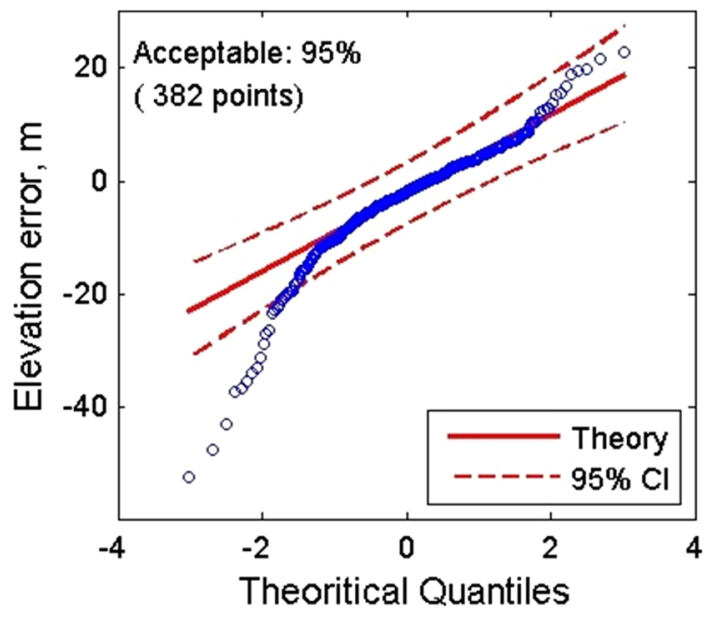

(b)

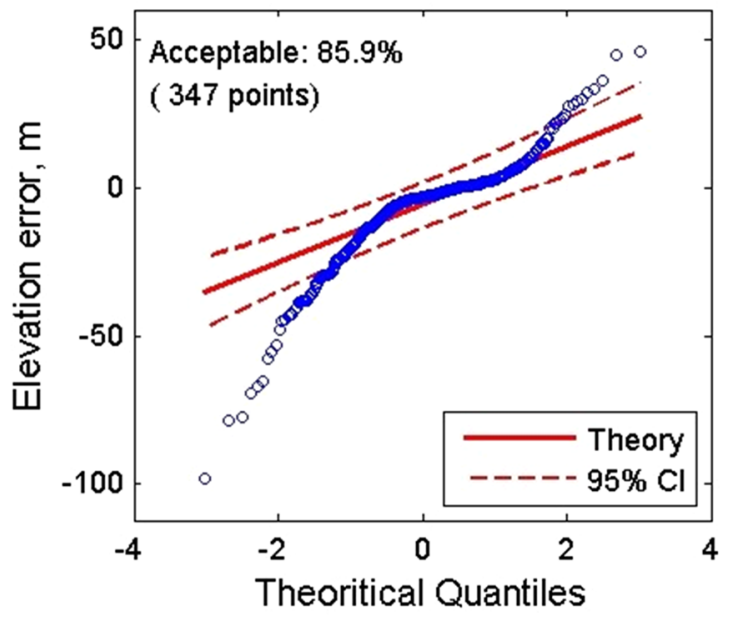

(d)

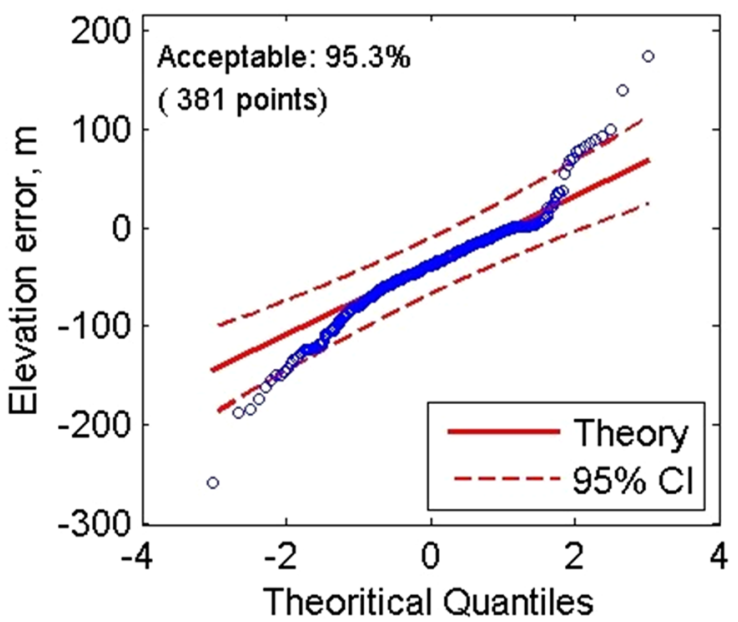

(f)

Fig. 5 Quantiles-Quantiles plots to show the error distribution for a GSI-DEM; b ASTER; c SRTM; d GMTED2010; e HtdroSHEDS; f GTOPO 30 
Table 4 Parameter of affine transformation based on multiple linear regressions for bias correction

\begin{tabular}{lrrrr}
\hline DEMs & \multicolumn{1}{l}{$\mathrm{a}$} & $\mathrm{b}$ & $\mathrm{c}$ & \multicolumn{1}{l}{$\mathrm{Z}_{0}$} \\
\hline GSI & -1.830 & 3.523 & 0.999 & 125.963 \\
ASTER & -3.188 & 3.629 & 0.993 & 301.737 \\
SRTM & -0.187 & 1.304 & 0.996 & -21.741 \\
GMTED & 0.467 & 0.341 & 0.991 & -78.566 \\
HydroSHEDS & -10.911 & 23.842 & 0.936 & 628.969 \\
GTOPO & -0.074 & 7.467 & 0.976 & -276.667 \\
\hline
\end{tabular}

Table 3 presents the statistical values of the elevation differences, including the minimum, maximum, mean, standard deviation values, and RMSE. The statistical value errors of GSI-DEM reveal a positive mean error of $0.08 \mathrm{~m}$. Figure $4 \mathrm{a}$ represented by the histogram shows the frequencies of the positive errors on a slightly positive skew. The slightly positive indicate that the GSI-DEM overestimated the observed terrain elevation. ASTER errors present the negative mean of $-3.122 \mathrm{~m}$ and the different elevation between ASTER DEM and GCP (Fig. 4b) following with a normal distribution. However, there is a slight error on the negative values which the GCPs elevation value is larger than the ASTER DEMs elevation. From the previous studies, the ASTER was reported by Hirt et al. (2010) on the negative bias to validate with the GCPs. The statistical values of the errors in SRTM show also a negative mean error of $-3.71 \mathrm{~m}$ in a slight negative bias on histogram (Fig. 4c), indicating that the SRTM underestimated the topographic elevation. These investigation were confirmed by previous studies ( $\mathrm{Li}$ et al. 2013; Zhao et al. 2010) on the negative bias for the SRTM. GMTED2010 errors reveal also a negative mean error of $-6.68 \mathrm{~m}$ for this study area. The histogram (Fig. 4d) of this DEM shows a small bias toward negative values on a normal distribution. The negative bias reveals that the GMTED2010 similarly underestimates the spatial distribution terrain elevation. The GMTED2010 was presented on the negative bias by Carabajal et al. (2011). The statistical values of errors in HydroSHEDS and GTOPO30 present also a negative mean error of -39.04 and $-40.89 \mathrm{~m}$, respectively. Figure $4 \mathrm{e}, \mathrm{f}$ on the histogram show the frequencies of negative error greater than the positive errors. A large negative bias is investigated in both histograms, indicating that the HydroSHEDS and GTOPO30 underestimated the observed data.

Figure 5 presents the Q-Q plots of elevation errors in six data sources. A reference line at $95 \%$ confidence intervals is along with upper and lower. The Q-Q plots for six DEMs indicate that the data were not conforming to normal distributed, representing a sigmoid-type function with a significant deviation from the fit line. The most observations present a strong deviation with the $95 \%$ confidence boundary. GSI-DEM has $93.2 \%$ of acceptable in the $95 \%$ confidence intervals (370 points from 418 points). ASTER has an acceptable data with 382 points of 418 points $(95 \%)$ while the SRTM can capture with $90 \%$ of 418 points (361 points). The conformable point with the $95 \%$ confidence intervals of GMTED2010 is 347 points $(85.9 \%)$ of total GCP data. HydroSHEDS and GTOPO30 have an acceptable point of 385 points and 381 points, respectively. All of the investigations reveal a deviation based on the $95 \%$ confidence intervals boundary.

A Linear transformation approach was applied in this study and it used to correct for shifting the bias between DEM and GCP. The inverse matrix algorithm (Marsh 2015) was used to obtain an optimized value (see Table 4) for $a, b, c$ and $Z_{0}$ of each DEM for bias correction. The $a$ parameter of GMTED is a positive value while five DEMs is a negative value between -0.07 and -10.91 . All of the DEM sources $b$ parameter is a positive value in the range $0.34-23.84$, and $c$ parameter is also the positive values are close to 1 . The $Z_{0}$ is the positive value on GSIDEM, ASTER, and HydroSHEDS, while this parameter of SRTM, GMTED2010 and GTOPO30 is the negative value. According to the value of the parameter from this transformation, the coordinate of the pixel has a relationship with the elevation based on the variation of parameter $a$ and $b$. Elevation all pixels in each DEM was recalculated by using the bias correction parameter.

After recomputation with transformation parameter, the comparison of the accuracy of all DEMs was recalculated (Table 3). Figure 6 shows a histogram of the modified DEM as six datasets that transformed to return a better accuracy than existing data set. The modified DEMs present a mean error close to zero, indicating that these data sets are unbiased. Figure 7 presents the difference between existing and modified DEM based on RMSE. The transformation approach greatly increased the accuracy of all DEM. The RMSE value is improved by $0.099 \mathrm{~m}$ for GSIDEM $(-1.66 \%), 0.85 \mathrm{~m}$ for ASTER $(-8.55 \%)$ and $0.77 \mathrm{~m}$ for SRTM $(-7.66 \%)$. The RMSE measured for differences of GMTED2010 is $1.48 \mathrm{~m}(-8.21 \%)$, while this value for HydroSHEDS is $15.31(-22.29 \%)$ and $15.93 \mathrm{~m}(-25.74 \%)$ for GTOPO30. The GSI-DEM is more accuracy than five DEMs model for all validation sources, but it is published only in Japan region. For the international source, the ASTER shows the best accuracy, while GTOPO30 is more accuracy than HydroSHEDS to compare with coarse resolution. 


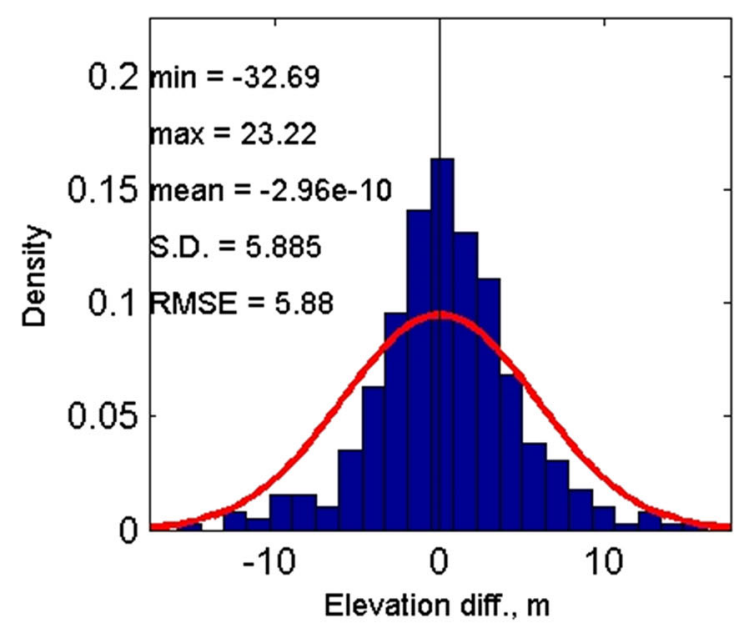

(a)

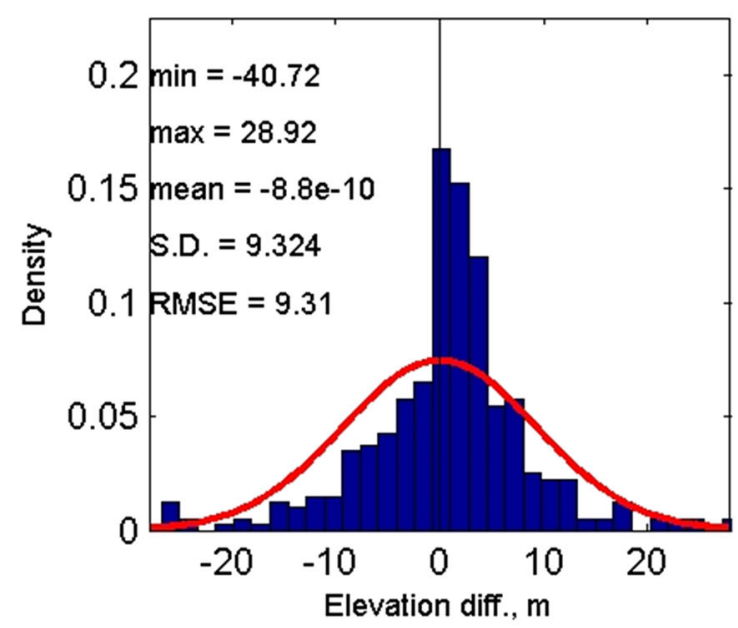

(c)

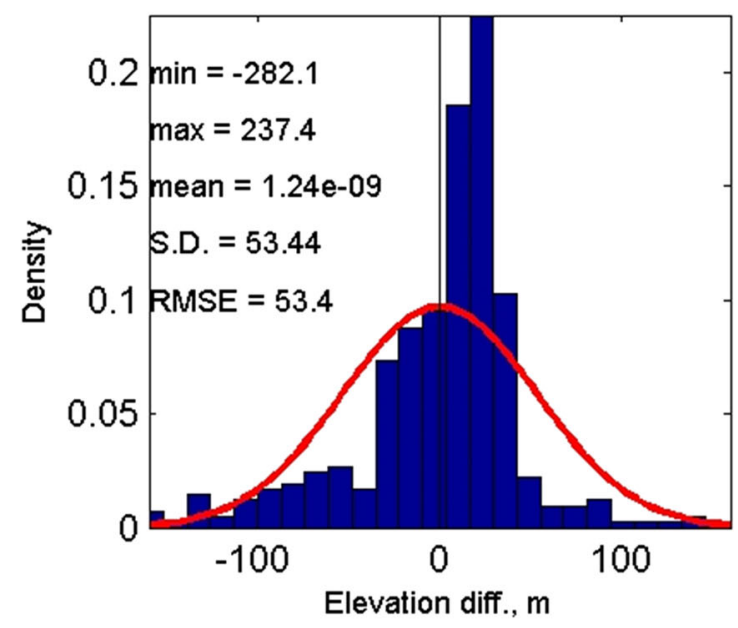

(e)

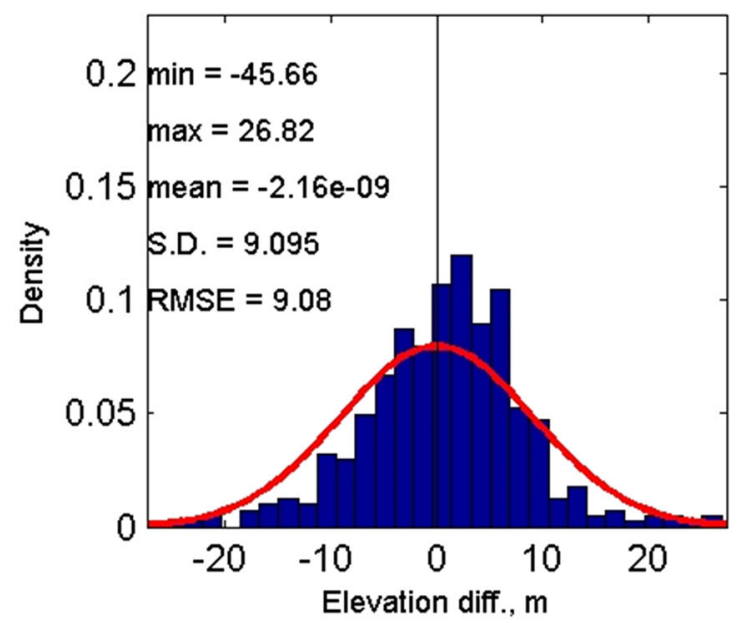

(b)

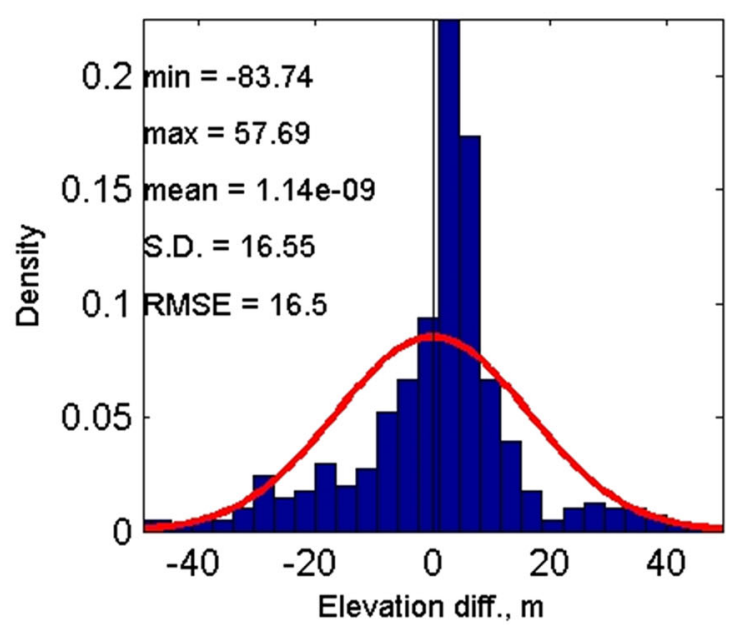

(d)

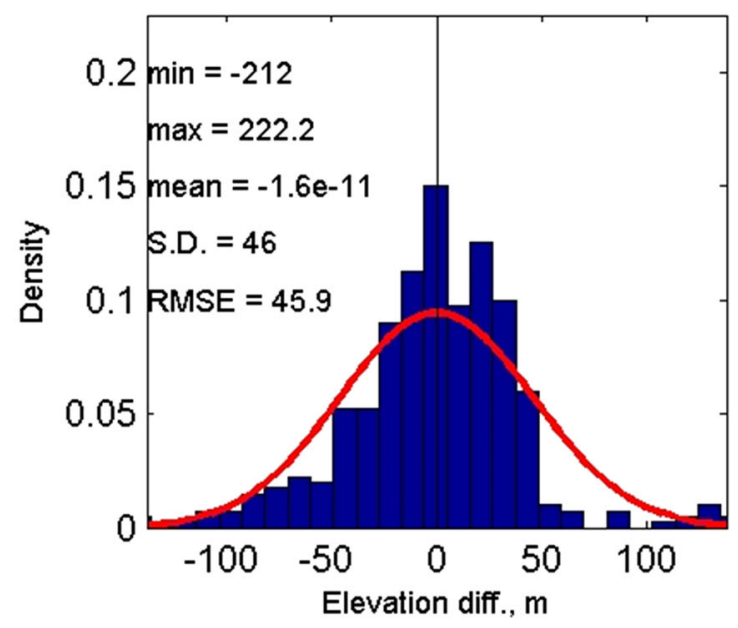

(f)

Fig. 6 Histograms of elevation errors and estimated basic statisticals after bias correction method. a GSI-DEM; b ASTER; c SRTM; d GMTED2010; e HtdroSHEDS; f GTOPO30 


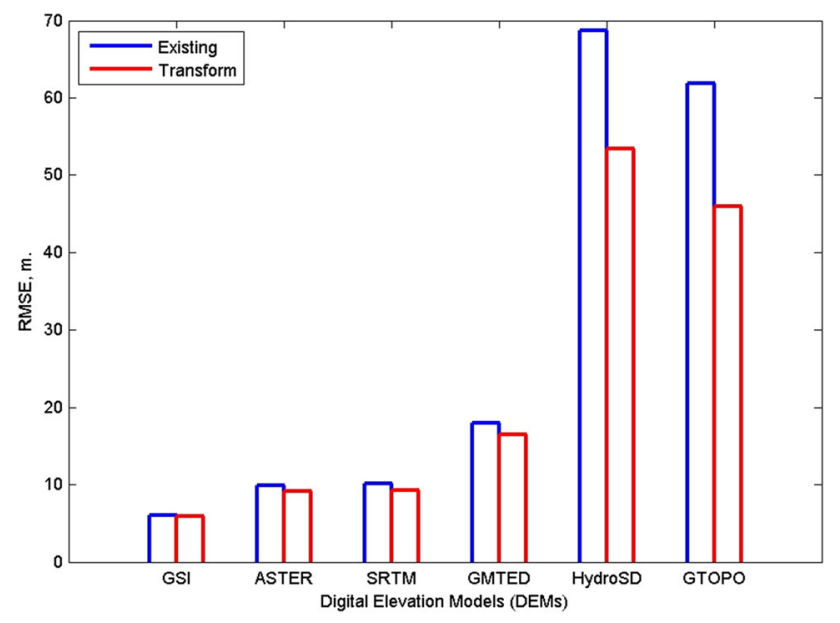

Fig. 7 RMSE are compared between before and after bias correction

The assessment of vertical accuracy of the five international DEMs exposes that the ASTER data displays a better vertical accuracy than the four DEM. The accuracy of ASTER is better than SRTM, which has been marked in previous studies. ASTER gives better accuracy and those results were concluded (Table 5) that were mentioned by Mukherjee et al. (2013). On the other hand, the large variations in global height precision are found in the examined DEMs literature. It shows that the DEMs on vertical precision depend on location, errors of reference point, terrain characteristics, and surface properties. Hence, this recommendation performs to an investigation about those factors. In addition, Table 3 exposes that the RMSE value of $9.3 \mathrm{~m}$ for SRTM are very similar to those described by Mukherjee et al. (2013). The ASTER GDEM presents the RMSE value about $9.08 \mathrm{~m}$ to close with Athmania and Achour (2014). According to the international DEMs, this study reports that the SRTM is lower accuracy to compare with ASTER and GMTED2010 for a fine resolution while a coarse resolution GTOPO30 is higher accuracy than HydroSHEDS pixel size of 15 arcsecond.

\section{Conclusions}

This study examined the quality of six digital elevation models GSI-DEM, ASTER, SRTM, GMTED2010, HydroSHEDS and GTOPO30 over the Shikoku Island in Japan, all of which are available free published data. First, the basic characteristics of the DEMs were described. Then, comparisons of the six DEMs were presented with vertical accuracy that was estimated by using GPS reference data (GCPs). Finally, DEM differences were discussed from the statistical assessment. For the evaluation of the accuracy, statistical approaches based on histograms and $\mathrm{Q}-\mathrm{Q}$ plots were presented and the error characteristics in six sources of DEM were investigated. After bias correction using a linear transformation, the validation statistics were recomputed for each DEM. The results for RMSE of terrain elevation are $5.87 \mathrm{~m}$ for GSI-DEM with GCPs on high definition resolution. For the fine resolution, the RMSE is $9.08 \mathrm{~m}$ for the ASTER, 9.31 for the SRTM and $16.53 \mathrm{~m}$ for GMTED2010. The RMSE of coarse resolution DEM is $53.37 \mathrm{~m}$ for HydroSHEDS and $45.94 \mathrm{~m}$ for GTOPO30. For all DEM sources, the transformed results suggest to unbias altitudes based on the mean error value. The top of the canopy has an effect to the sensors, ASTER, and SRTM (Athmania and Achour 2014). That is the reason of negative bias that occurs in ASTER and SRTM, including other test DEM. In conclusion, this study has revealed the importance point of computing validation statistics for DEM before and after bias correction. Further study can be prepared to evaluate the bias transformation based on the reasons for their land cover occurrence.
Table 5 Varying reports height accuracies for the ASTER GDEM2 and SRTM v4.1 DEMs

\begin{tabular}{|c|c|c|c|c|}
\hline \multirow[t]{2}{*}{ Study areas } & \multicolumn{2}{|c|}{ ASTER GDEM2 } & \multicolumn{2}{|c|}{ SRTM v4.1 } \\
\hline & $\mathrm{ME}$ & RMSE & ME & RMSE \\
\hline Indonesia, Karian dam (Suwandana et al. 2010) & $\mathrm{n} / \mathrm{a}$ & 5.68 & $\mathrm{n} / \mathrm{a}$ & 3.25 \\
\hline Australia, Bare areas (Rexer and Hirt 2014) & -4.22 & 8.05 & 2.69 & 3.43 \\
\hline Italy, Southern Sardinia (Pulighe and Fava 2013) & $\mathrm{n} / \mathrm{a}$ & 12.95 & $\mathrm{n} / \mathrm{a}$ & $\mathrm{n} / \mathrm{a}$ \\
\hline China, Tibetan Plateau (Li et al. 2013) & -5.9 & 14.1 & 0.9 & 8.6 \\
\hline India, Shiwalik Himalaya (Mukherjee et al. 2013) & -2.58 & 6.08 & -2.94 & 9.2 \\
\hline Tunisia, Anaguid (Athmania and Achour 2014) & -2.32 & 5.3 & 0.48 & 3.6 \\
\hline Algeria, Tebessa (Athmania and Achour 2014) & -1.02 & 9.8 & 0.48 & 8.3 \\
\hline
\end{tabular}


Acknowledgments The Authors express their sincere gratitude to NASA, NIMA, METI, USGS and CGIAR for making this work possible by processing and distributing free the DEMs data to the scientific community. The authors would like to thank the Kochi University of Technology has been supported in part by Takagi laboratory.

\section{References}

ASTER GDEM Validation Team (2012) ASTER Global DEM ValidationSummary Report. http://www.ersdac.or.jp. Accessed on 19 Oct 2012

Athmania D, Achour H (2014) External validation of the ASTER GDEM2, GMTED2010 and CGIAR-CSI-SRTM v4.1 free access digital elevation models (DEMs) in Tunisia and Algeria. Remote sens 6:4600-4620

Carabajal CC, Harding DJ, Jean-Paul B, Danielson JJ, Gesch DB, Suchdeo VP (2011) Evaluation of the global multi-resolution terrain elevation data 2010 (GMTED2010) using ICESat geodetic control. In: Proceedings of SPIE-The international society for optical engineering. Nanjing

Danielson JJ, Gesch DB (2011) Global multi-resolution terrain elevation data 2010 (GMTED2010), US geological survey openfile report. US Geological Survey, Sioux Falls

Dhakal AS, Amanda T, Aniya M (2000) Landslide hazard mapping and its evaluation using GIS: an investigation of sampling schemes for a grid-cell based quantitative method. Photogramm Eng Remote Sens 66:981-989

Fisher PF, Tate NJ (2006) Causes and consequences of error in digital elevation models. Prog Phys Geogr 30:467-489

Forkuor G, Maathuis B (2012) Comparison of SRTM and ASTER derived digital elevation models over two regions in ghanaimplications for hydrological and environmental modeling. In: Piacentini $\mathrm{T}$ (ed) Studies on environmental and applied geomorphology. InTech, Rijeka, pp 219-240

Gonga-Saholiariliva N, Gunnell Y, Petit C, Mering C (2011) Techniques for quantifying the accuracy of gridded elevation models and for mapping uncertainty in digital terrain analysis. Prog Phys Geogr 35:739-764

Hebeler F, Purves RS (2009) The inuence of elevation uncertainty on derivation of topographic indices. Geomorphology 111:4-16

Höhle JH, Höhle M (2009) Accuracy assessment of digital elevation models by means of robust statistical methods. ISPRS J Photogramm Remote Sens 64:398-406

Hirt C, Filmer MS, Featherstone WE (2010) Comparison and validation of the recent freely available ASTER-GDEM ver1 SRTM Ver4.1 and GEODATA DEM-9 s Ver3 digital elevation models over Australia. Aust J Earth Sci 57:337-347

Ishida K, Takagi M (2010) Change detection of surface elevation by ALOS/PRISM for disaster monitoring. In: Proceedings of ISPRS 38th. Kyoto

Jarvis A, Rubiano J, Nelson A, Farrow A, Mulligan M (2004) Practical use of SRTM data in the tropics: comparisons with digital elevation models generated from cartographic data. International Centre for Tropical, Agriculture (CIAT), Cali, p 32

Jarvis A, Reuter HI, Nelson A, Guevara E (2012) Hole-filled SRTM for the globe version 4. CGIAR-CSI SRTM $90 \mathrm{~m}$ Database 2008. http://srtm.csi.cgiar.org. Accessed on 1 July 2012

Kolecka N, Kozak J (2013) Assessment of the accuracy of SRTM Cand X-Band high mountain elevation data: a case study of the Polish Tatra Mountains. Pure appl Geophys. doi:10.1007/ s00024-013-0695-5

Kuriakose E, Viswan A (2013) Remote sensing image matching using sift and a transformation. Int J Comput Appl 80:22-27
Kyaw SO, Takagi M (2010) Estabkishment of validation _eld for satellite remote sensing in Shikoku, Japan. In: Proceedings of ISPRS 38th, Kyoto

Lee SJ, Komatitsch D, Huang B, Tromp J (2009) E_ect of topography on seismic-wave propagation: an example from north Taiwan. Bull Seismol Soc Am 99:314-325

Lehner B (2013) Quality assessment. In: HydroSHEDS Technical documentation, 1st ed. World Wildlife Fund US: Washington DC, p 1314

Li J, Chapman MA, Sun X (2006) Validation of satellite-derived digital elevation models from in-track IKONOS stereo imagery. Toronto, Ontario Ministry of Transportation

Li P, Shi C, Li Z, Muller JP, Drummond J, Li X, Li T, Li Y, Liu J (2013) Evaluation of ASTER GDEM using GPS benchmarks and SRTM in China. Int J Remote Sens 34:1744-1771

Marsh D (2015) Homogeneous coordinates and transformations of the plane. In: Applied geometry for computer graphics and CAD. http://www.springer.com/978-1-85233-801-5. Accessed on 2005

Miliaresis GC, Paraschou CVE (2005) Vertical accuracy of the SRTM DTED level 1 of Crete. Int J Appl Earth Obs Geoinform 7:49-59

Mukherjee S, Joshi PK, Mukherjee S, Ghosh A, Garg RD, Mukhopadhyay A (2013) Evaluation of vertical accuracy of open source digital elevation model (DEM). Int J Appl Earth Obs Geoinform 21:205-217

Nawarathna NMNSB, Ao TQ, Kazama S, Sawamoto M, Takeuchi K (2001) Inuence of human activities on the BTOPMC model simulations in large-scale watersheds. In: XXIX LAHR congress proceeding, volume Theme A

Nikolakopoulos KG, Kamaratakis EK, Chrysoulakis N (2006) SRTM vs. ASTER elevation products comparison for two regions in Crete, Greece. Int J Remote Sens 27:4819-4838

Pakoksung K, Takagi M (2015) Remote sensing data application for ood modeling. J Appl Surv Technol 26:115-122

Pulighe G, Fava F (2013) DEM extraction from archive aerial photos: accuracy assessment in areas of complex topography. Eur J Remote Sens 46:363-378

Rexer M, Hirt C (2014) Comparison of free high resolution digital elevation data sets (ASTER GDEM2, SRTM v2.1/v4.1) and validation against accurate heights from the Australian National Gravity Database. Aust J Earth Sci 61:213-226

Suwandana E, Kawamura K, Sakuno Y, Kustiyanto E, Raharjo B (2010) Evaluation of ASTER GDEM2 in comparison with GDEM1, SRTM DEM and topographic-map-derived DEM using inundation area analysis and RTK-dGPS data. Remote Sens 4:2419-2431

Tachikawa T, Kaku M, Iwasaki A (2011) In ASTER GDEM Version 2 validation report, 2nd ed. Japan, p A1A24

Uda K, Takagi M (2010) Suitable type of GCP for accuracy registration of high resolution satellite data. In: Proceedings of the 31th Asian conference on remote sensing. Hanoi

USGS GTOPO30 (2008) http://lta.cr.usgs.gov/GTOPO30. Accessed on Jan 2015

USGS Data sources of HydroSHEDS (2008) http://hydrodheds.cr. usgs.gov/datasource. Accessed on 31 Jan 2008

Zandbergen PA (2008) Positional accuracy of spatial data: nonnormal distributions and a critique of the national standard for spatial data accuracy. Trans GIS 12:103-130

Zhang J, Zhang Z (2011) Strict geometric model based on a transformation for remote sensing image with high resolution. In: Proceedings of ISPRS 34th. Sydney

Zhao G, Xue H, Ling F (2010) Assessment of ASTER GDEM performance by comparing with SRTM and ICESat/GLAS data in Central China. In: Proceedings of the 18th international conference on geoinformatics, Beijing 